\title{
Development of Learning Model of Youtube-Based Learning in Light Vehicle Electricity Maintenance Subject
}

\author{
Indra Saputra*, Muchlas, Bambang Nor Achsan \\ Universitas Ahmad Dahlan, Jl. Pramuka No. 42, Pandeyan, \\ Umbulharjo, Yogyakarta, Indonesia. \\ *Corresponding Author, e-mail: indra_saputra002@yahoo.co.id
}

\begin{abstract}
This study aims to develop a learning model of Youtube-Based Learning to facilitate the learning habits of digital-age students. This research used the research and development method. The research steps were analysis of potential and problems, data collection, product design, design validation, design revisions, limited implementation test, revisions, implementation tests, revisions, and mass production. Subject research was the students of class XI of Light Vehicle Engineering at SMK Muhammadiyah 1 Playen. Research data collection used closed questionnaire, open questionnaire, and integrated with interviews and observations. The data analysis technique used the effect size test. The results showed that the validity of Youtube-Based Learning included in the very feasible category to apply. The contribution given by Youtube-Based Learning on student learning outcomes was $58 \%$. Other results showed that students and teachers gave positive responses to the learning model of Youtube-Based Learning.
\end{abstract}

Keywords: learning model, Youtube-Based Learning, electricity maintenance.

How to Cite: Saputra, I., Muchlas, \& Achsan, B. N. (2020). Development of Learning Model of YoutubeBased Learning in Light Vehicle Electricity Maintenance Subject. Journal of Vocational Education Studies, 3(1), 1-12. DOI: https://doi.org/10.12928/ joves.v3i2. 2652.

\section{INTRODUCTION}

Today, education experiences the changing of the era with various challenges such as the development of information technology which always has various effects on education. Education, especially in the XXI century, has been characterized by the presence of information technology whose impact has changed various basic aspects of life (BSNP, 2010).

An example of significant changes caused by the development of information technology is the phenomenon of human dependence on information technology. This phenomenon can be seen from several data related to the increasing in internet access which is so drastic. The results of a survey conducted by the Indonesian internet service provider association in 2017 showed that the number of internet users in Indonesia had reached 143.26 million. Penetration of internet users is dominated by ages 13-18 years which is 76 percent and they spend an average of 1 to 3 hours per day to access the internet (APJII, 2017). Based on preliminary studies conducted by the researcher, ages 13 to 18 years are the age categories of junior high school students to the age of vocational high school students.

Other references describe the types of content accessed by internet users in Indonesia. The first rank of content most frequently accessed is Youtube as much as 88 percent, then Whatsapp as much as 83 percent, Facebook as much as 81 percent and followed by other content such as Instagram, Line, Twitter, and other content (Hootsuite, 2019).

The high internet access can ideally be utilized by education managers to improve the quality of learning. The ability to use the technology to support learning outcomes is one of

Received September 03, 2020; Revised November 2, 2020; Accepted November 2, 2020 
the pedagogical competencies that should be owned by a teacher as an educator. Pedagogical competence requires a teacher to be able to utilize information and communication technology for maximizing the learning process to facilitate the development of students' potential to actualize the various potentials they have (Wahyudi, 2012).

The rapid development of technology can provide a positive impact. One of the most striking features of the 21st century is the increasingly interconnected world of science triggering the synergies between them faster. The use of information and communication technology (ICT) in the education field has proven to be increasingly narrowing space and time as the determinant of the speed and success of mastering science by humans (BSNP, 2010).

Today, the site frequently visited and has the potential to contribute a positive impact on education is Youtube. YouTube is the world's largest provider of user-based video content (Zhu, Wattenhofer, \& Wattenhofer, 2012). Some research has been done to prove the benefits that can be taken from YouTube in the education process. A study describes that the use of YouTube channels in the teaching process can increase students' motivation and confidence. Teaching and learning process involving current technology is proven to be an effective way to improve students' general performance with significant results (Sari, 2017). Learning using Youtube playlists has been designed to be able to meet learning objectives in all areas of learning such as cognitive, affective, and psychomotor in online classrooms. Besides, teachers can also create an interactive video game, simulations, or tutorials according to the learning needs (Snelson, 2011).

The ideal conditions related to the positive impact of the development of technology on education described in the previous elaboration have not been able to be realized in the actual conditions. The real condition of the implementation of the education process is still far from the ideal conditions expected, especially in the use of technology in a learning activity. We can analyze this phenomenon from some research data. Research on teachers found that 62 percent of elementary school, junior high school, senior high school, and vocational school teachers rarely use ICT for learning needs. 35 percent of teachers lack mastery of ICT, while 10 percent of teachers state that the facilities and infrastructure are less supportive in learning (Syukur, 2014).

Some facts related to the lack of use of information technology were also conveyed by the Ministry of Education and Culture that only 40 percent of non-information and communication technology teachers were ready to implement the technology (Suharwoto, 2018).

The low of ICT usage is also described by BPS data which shows that the proportion of schools having internet access according to the type of internet connection is 76 percent and that facility is used by 72 percent of students to access the internet at school, while on the other hand, the proportion of teachers having good qualifications in ICT only 10 percent (BPS, 2018). This phenomenon indicates that teachers have not been able to facilitate the learning habits of digital age students who have a dependency on the internet.

Researchers conduct a preliminary study to uncover the problems that occur in schools. The results illustrate that the students have less enthusiastic about participating in the learning process. This is indicated by the phenomenon of many students who are busy with their smartphones when the process of delivering the material done by the teachers. A similar condition also occurs in light vehicle electricity maintenance subjects, because, based on interviews with students, electricity subjects are subjects that are difficult to understand when compared to other subjects. 
As the following step, Problems found by researchers in the preliminary study are followed up with an analysis step that aims to uncover various trends related to the problem. These trends serve as the basis for planning solutions that will be executed in this research.

The first analysis relates to the low enthusiasm of students to participate in learning. Based on the analysis conducted by researchers adjusted to the real conditions in the field, the low enthusiasm of students is caused by the new perceptions owned by students. This new perception relates to the concept of information packaging attracting the students. The dominance of information technology in the presentation of information provides a special interest for students because the information obtained is interesting, instant, simple, and able to provide information based on needs.

Student interest in the presentation of information based on information technology is evidenced by several factual conditions in the learning process in class. For example, in completing a task given by a teacher, students are more interested to find the answers through the internet such as Google and Youtube. On the other hand, if the assignment is practical, students will access YouTube more as a source of answers due to the availability of various explanatory video material, tutorials, and simulations giving easier ways for students in practical activities. Very few students were found looking for a reference for the answer by reading the material provided. These conditions emphasize that students are more comfortable consuming audiovisual information than just absorbing information from reading, listening, or discussion.

The factual data above is also strengthened by expert statements. Cilliers stated that the brains of digital age students included in the generation $\mathrm{Z}$ category have a complex and sophisticated special network of visual information, and as a result, the part of the brain responsible for visual abilities is far more developed so that visual learning is easier to understand effectively. Listening models learning, such as lectures and discussions, are highly disliked by the Generation Z group, whereas learning with interactive game nuances, collaborative projects, and challenges will be more acceptable and preferred by the Generation Z (Cilliers, 2017).

Based on the problems that have been revealed, the researchers intend to develop a Youtube-Based Learning learning model to facilitate the learning habits of digital age students who prefer to use the internet.

\section{RESEARCH METHOD}

The type of this research is research and development (R\&D) which aims to produce certain products, and test the effectiveness of these products. This research was conducted at SMK Muhammadiyah 1 Playen Gunungkidul Yogyakarta for five months from September 2019 to January 2020. The validation test subjects in this study were learning experts and material experts as well as teachers, while the test subjects for the implementation of the models were light vehicle engineering students in class XI SMK Muhammadiyah 1 Playen. The object of this study is the subject of light vehicles' electricity maintenance and learning models.

Data analysis techniques used in this study were adjusted to each stage of each research. The detailed explanation is as follows:

1. Techniques of potential and problem data analyzing

Potential and problem data are collected through interviews and direct observation in the learning process. The data obtained at this stage is qualitative. The data analysis technique used is the triangulation method. The researcher examines the validity of potential and problem data by collecting similar data but using different data collection techniques or methods. This technique executed to confirm the results of teacher

Volume 3, Number 2, November 2020 
interviews with observations of factual conditions in the learning process. This analysis technique aims to reveal whether the two data are mutually supporting or weakening.

2. Data analysis techniques in the design validation test

The design validation test process is carried out using a closed questionnaire filled out by learning experts, material experts, and teachers. The type of data obtained at this stage is quantitative so the data analysis technique used is quantitative descriptive analysis. This analysis technique aims to reveal the feasibility of learning model design based on data given by experts and teachers.

3. Data analysis techniques in limited implementation test

The limited implementation test is carried out by implementing the learning model that has been developed to a limited number of students. In this step, limited implementation test data is collected using open questionnaires and direct observation in the learning process. Data are categorized into qualitative data. The data analysis technique used is the triangulation method by confirming the questionnaire data filled out by students with the observation data. This step is designed to be able to test whether the data given by students through an open questionnaire is in line with the factual conditions in class or not.

4. Data analysis techniques in the real implementation test

The real implementation test of Youtube-Based Learning in this study uses a quasiexperimental design with a pretest-posttest control group design. This quasiexperimental design was carried out by comparing the control group with the experimental group. A control group is a group of students who are taught using a learning model that does not utilize Youtube, while the experimental group is students who are taught using Youtube-Based Learning. The comparison process of the two groups is to find out the contribution of Youtube-Based Learning to the student learning outcomes.

Data analysis techniques in this step are grouped into two categories namely prerequisite test and data implementation test analysis. The detailed explanation is as follows:

a. Prerequisite Test

The prerequisite tests in this study include several stages such as data normality test, paired sample t-test, homogeneity test, and independent-sample t-test.

b. Analysis of implementation test data

The effect size test was chosen as the appropriate analysis technique in the analysis of the implementation test data. Effect size test is conducted to determine the size of contribution given by the Youtube-Based Learning to the student learning outcomes. This test is carried out using an effect size calculator that can be accessed online. The effect size calculator was designed by Dr. Lee A. Becker. The next step that needs to be done is the conversion of the calculation results to the Cohen's value in the following table: 
Table 1: Cohen's d value interpretation criteria (Becker, 2000)

\begin{tabular}{lcc}
\hline Cohen's Standard & Effect size & Percentage (\%) \\
\hline \multirow{4}{*}{ High } & 2,0 & 97,7 \\
& 1,9 & 97,1 \\
& 1,8 & 96,4 \\
& 1,7 & 95,5 \\
& 1,6 & 94,5 \\
& 1,5 & 93,3 \\
& 1,4 & 91,9 \\
& 1,3 & 90 \\
& 1,2 & 88 \\
& 1,1 & 86 \\
Moderate & 1,0 & 84 \\
& 0,9 & 82 \\
& 0,8 & 79 \\
Low & 0,7 & 76 \\
& 0,6 & 73 \\
& 0,5 & 69 \\
\hline
\end{tabular}

\section{RESULTS AND DISCUSSION}

\section{The results of the development of the learning model of Youtube-Based Learning}

The final result of the development of the learning model of Youtube-Based Learning has been through the validation stage and the revision stage based on the suggestions from the validator. Youtube-Based Learning is designed to be able to fulfill three functions of the learning model such as the planning function, the implementation function, and the evaluation function. Each function is divided into several stages of learning. The composition of Youtube-Based Learning is described in the following diagram: 


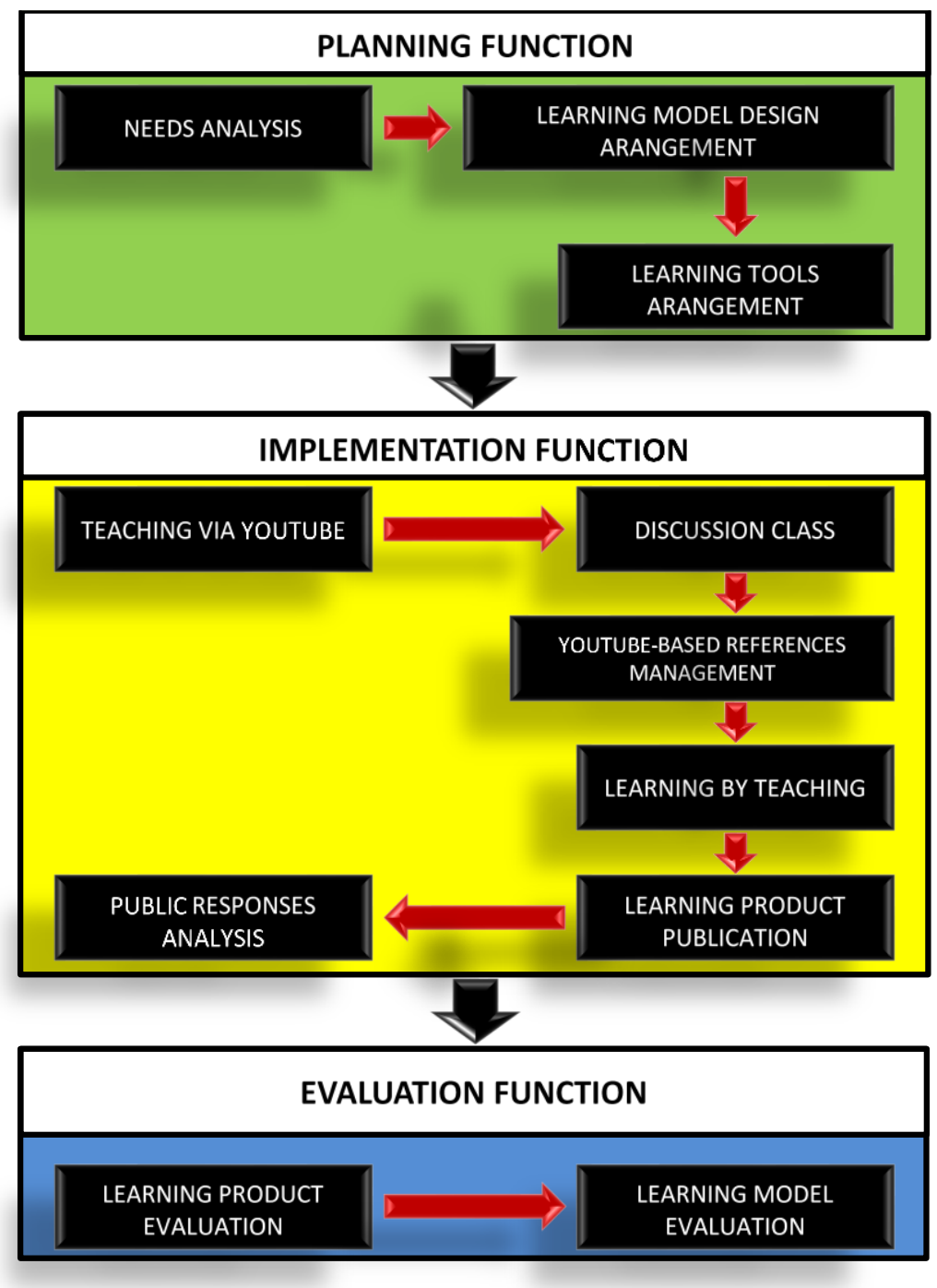

Figure 1. The diagram of Youtube-Based Learning

\section{Description of the Function of the Youtube-Based Learning}

In an ideal condition, the learning model has three functions, but what will be presented in more depth in this study focuses on the implementation function and followed by the evaluation function. The scope of this function has six steps such as teaching via Youtube, discussion classes, managing Youtube-based references, learning by teaching, product publications, and public response analysis. The evaluation function includes learning product evaluation and learning model evaluation. Explanation of each stage of the function is as follows:Availability of Physical Facilities/Simple Machines Instructional Resources for Marketing Trade Subject in Secondary Schools.

\section{a. Teaching via Youtube}

Teaching through Youtube is the first step in the process of implementing Youtube-Based Learning. Teaching through Youtube is done to maximize the use of ICTs in learning. It also aims to be able to facilitate the learning needs of digital age students who have a dependency on ICT. The teaching process through Youtube also aims to improve teacher competency in the ICT field because the teacher should make a learning video first then 
upload it to Youtube. After the video upload process is carried out, students are instructed to access the learning video and learn it independently outside the classroom.

b. Discussion class

The discussion class is the second stage after the teaching process through Youtube is implemented. The discussion class is designed to increase students' enthusiasm for learning. This learning design is a real manifestation of the students centered learning concept. Discussion class activities are spaces provided for students to convey things that have not been understood by students when understanding learning videos outside the classroom. This discussion class is an achievable strategy to reduce teacher dominance in learning and maximize the role of students in collecting information to overcome difficulties found through discussion forums. The expectation of this learning concept is the realization of a learning model that can provide flexibility for students to maximize the students' problem solver skills.

c. Managing Youtube-based references

Managing Youtube-based references is a follow-up step after the discussion class is carried out. This activity also aims to provide solutions to students' problems that have not been able to be resolved by discussion class forums. In managing Youtube-based references, students are guided by the teacher to manage information in the form of Youtube-based videos. In this activity, students are trained on how to explore the accurate information based-on needs and sort out information from the millions of information content available on Youtube. This activity is also expected to be able to train students' skills in overcoming the problems to produce reliable problem solver skills within students. Management of Youtube-based reference also provides educational value for students related to positive internets, such as maximizing the utilization of the internet for learning and minimizing the access of internet negative content.

d. Learning by teaching

Learning by teaching is a form of the assignment given in learning. The learning task given to students is making learning videos based on the competencies being studied. In this assignment activity, students are instructed to demonstrate what they learn and understand than convert it in the form of learning videos. This activity aims to maximize the level of student understanding of learning material. In this activity, students act as the role of learning resource when making learning videos. This task requires students to understand the material well in advance so that students can provide a clear explanation of the learning material to the audience. This step is designed to increase the level of student understanding and be more inherent in students' memories.

e. Learning product publications

Learning product publication is an appreciation step for students' products in the learning process. Through this step, students are expected to be more motivated to produce a worthy product to be accessed by people. Product publication activity also provides educational value to the students related to how to promote a product that has been produced. Through the process of publishing and promoting this product, it is expected that many people are interested in accessing the student's products. This learning design is also expected to be able to sharpen the students' professional mentality in creating the best product based on their creativity. Students' learning video products are published through a Youtube account created by each student. Through Youtube, students can analyze how the public response to their product.

f. Analysis of public responses

Public response analysis aims to analyze how public responses to the students' products. The process of public response analysis is done by observing the comments column available on the Youtube page. On the comments page, viewers give responses related to the learning video presented. Responses given by viewers can be either positive or negative responses. The results of the public response analysis can be used as evaluation

Volume 3, Number 2, November 2020 
material for students and teachers so that improvements can be carried out to maximize the product. Suggestions obtained in this process also teaches students about the products needed and suitable for public consumption so students can meet those needs.

g. Learning product evaluation

Learning product evaluation is an evaluation activity carried out by the teacher to the students' learning video products. This product evaluation process aims to determine the feasibility of student products. The results of the product evaluation can be used as a reference for teachers to assist students in the product improvement process. Through this step, students are expected to be able to produce better learning video products.

h. Evaluation of learning models

Evaluation of learning models is an evaluation step that covers all aspects of the learning model. It aims to analyze the feasibility of the learning model developed. The evaluation process includes several stages such as design validation by expert judgment, limited implementation test, expanded implementation test, and independent sample t-test using the control class compared with the experimental class. Each step of the evaluation is carried out to minimize the deficiencies of the learning model developed.

\section{The results of expert judgment validation of learning model}

The results of the validation given by the learning model expert are presented in the following figure:

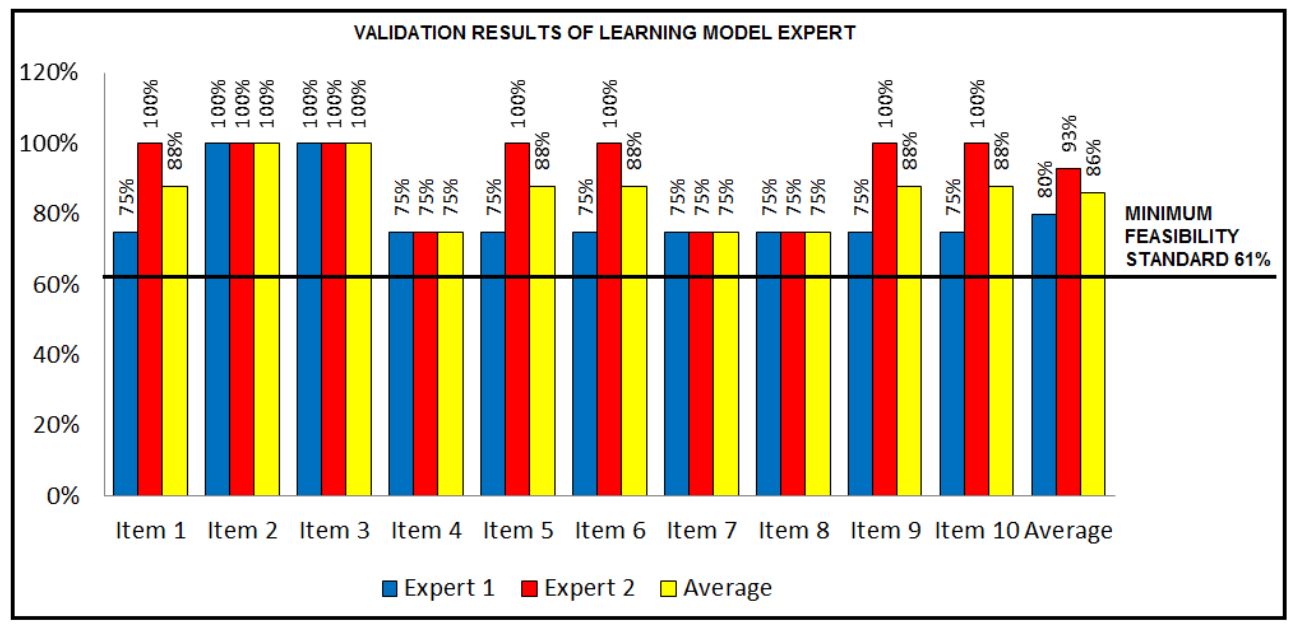

Figure 2. Validation results of the learning model expert

Validation results of material expert

The validation results given by the material experts are presented in the following figure: 


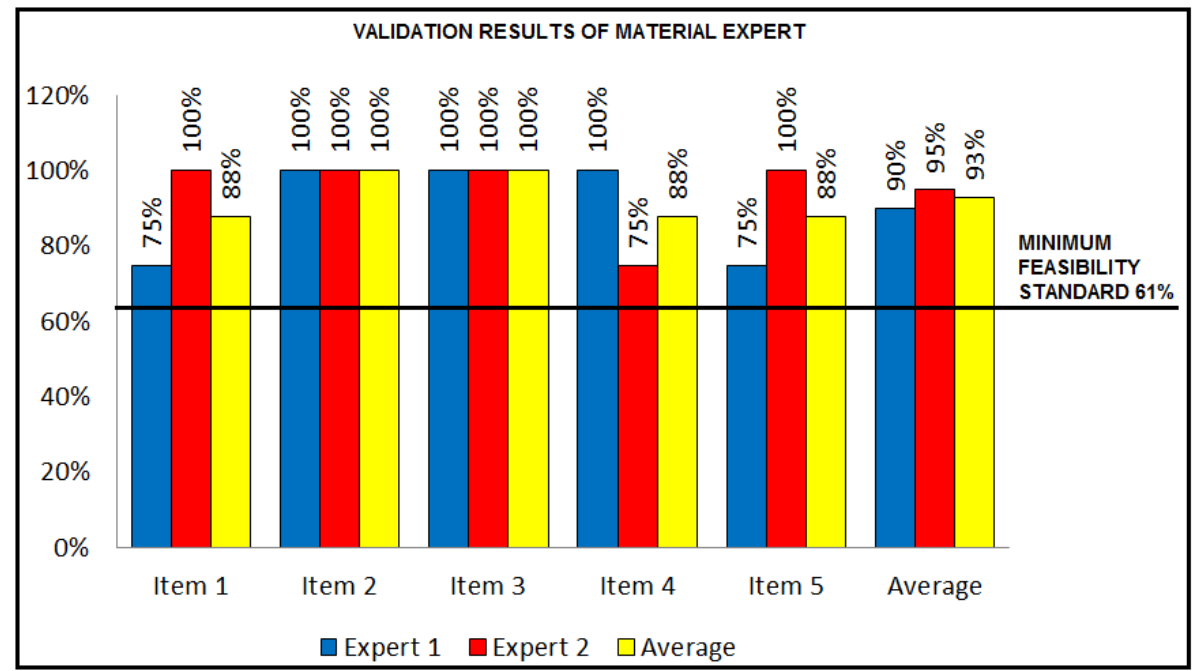

Figure 3. Validation results of material expert

Figure 3 describes the scores for each item as well as the overall average. The average score given by material expert validators was 93\%. Based on the eligibility standard, the score illustrates that the material validity of Youtube-Based Learning is included in the very feasible category.

\section{Results of the implementation of Youtube-Based Learning.}

The implementation of learning models begins with the creating of learning videos conducted by the teacher. Then, the learning video is uploaded on the Youtube page and then students are instructed to access and learn the learning video. The results of creating learning videos by teachers are as follows:

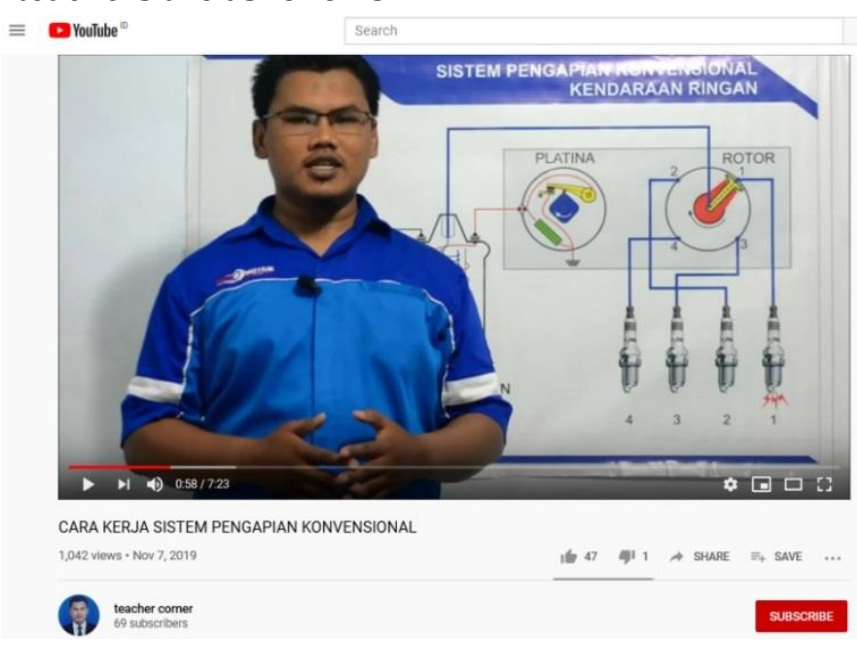

Figure 4. Result of the learning videos uploaded

Learning videos uploaded could be accessed at the link https://youtu.be/WTLaQnEulPU.

In the next step, as a form of assignment in learning, students are given the task to make learning videos as part of the learning assessment. Examples of the results of learning videos made by students are as follows: 


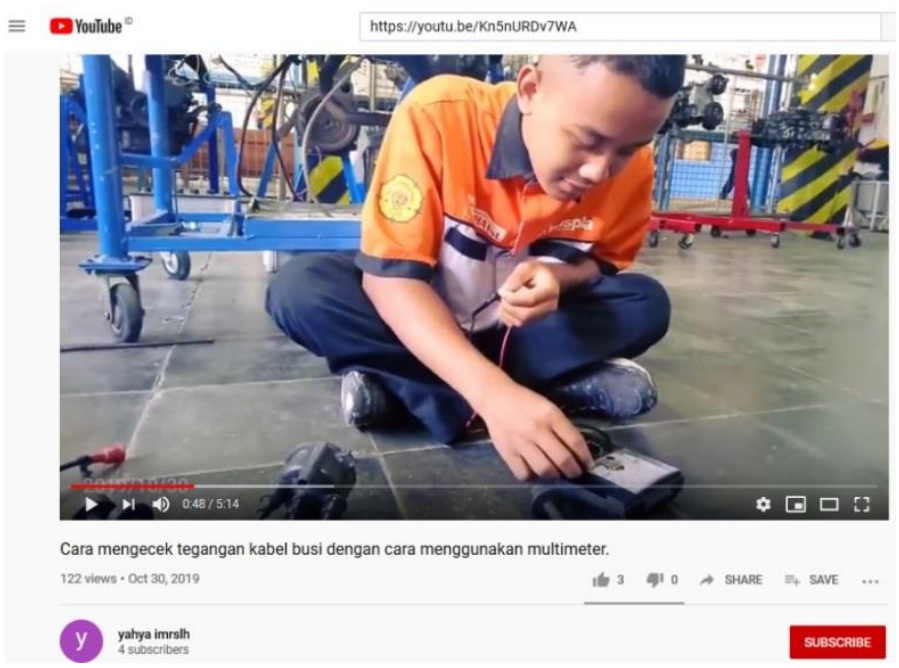

Figure 5. Example of students' learning video

Figure 5 describes one example of the results of learning videos made by students. In the video, students explain how to check the spark plug wire resistance using a multimeter. The learning videos made by these students are generally included in the good category that already meets several criteria such as explanations given that are easy to understand, maximum video quality, and also meets the procedures for repair tools application standard and work safety procedures properly such as using work clothes.

In more detail, we can observe that the Youtube account created by students still has a few subscribers, but the number of video viewers is quite a lot, about 122 views and get 3 likes. This is a good start for students. The evaluation given by the teacher is that the students need to maximize the editing process to support the quality of learning videos. Other examples of student learning videos can be accessed at the following video link:

https://youtu.be/3PpvHgtz67g https://youtu.be/EvYUR6s2cyo https://youtu.be/rPDsEqI5]i8 https://youtu.be/qdZf4mCr678 https://youtu.be/YzOvn5Q5XEQ https://youtu.be/gVIAUWSyBB0 https://youtu.be/5tEwokP6i98 https://youtu.be/R70JRBQ8sGo https://youtu.be/iZVE-TeUiO0 https://youtu.be/6x9hNkGiuHM https://youtu.be/o3umkUvCfKA https://youtu.be/ZXJYxyOi-kQ https://youtu.be/Kn5nURDv7WA https://youtu.be/Z9d5NOybxxk https://youtu.be/6KXm9GDZR4o https://youtu.be/d fHFDcSLlo https://youtu.be/Exr A7M7Ldk https://youtu.be/WjsvsZ4bxcQ https://youtu.be/ZnVsWk9111c https://youtu.be/-Z8LtY8nnig https://youtu.be/LAo4HVASjuM https://youtu.be/MHIkrzVl7U https://youtu.be/IiI4g980XKg https://youtu.be/-VZu6aTIU84 
https://youtu.be/aRTf RAPP2M

https://youtu.be/b7NKrp3WtoI

https://youtu.be/lvRX5FOPX2o

The student assignment process is followed by evaluating student learning outcomes using tests. Then, the test results are analyzed to measure the contribution of YoutubeBased Learning to the student learning outcomes.

\section{Data Normality Test}

Data normality test is carried out to find out whether the student value data in the YoutubeBased Learning model shows the normal distribution or not. This step is a prerequisite determining the next step of data analysis. Data normality test results are as follows:

Table 2. Result of data normality test

\begin{tabular}{lcc}
\hline & Test of Normality & \\
\hline Class & Sig. & Information \\
\hline Pre-test of the experiment class & 0,082 & Normal \\
Post-test of the experiment class & 0,121 & Normal \\
Pre-test of the control class & 0,200 & Normal \\
Post-test of the control class & 0,200 & Normal \\
\hline
\end{tabular}

The normality test output results show that the value of Sig.> 0.05 on all test points, it can be concluded that the data distribution is normal. Because the research data distribution is normal, so the next data analysis can be executed by using the parametric statistical test (paired-sample t-test and independent-sample t-test).

\section{Paired Sample t-test}

The Paired sample t-test conducted in this study aims to analyze whether there is a difference between student learning outcomes before and after participating in learning using Youtube-Based Learning. These differences can indicate the influence of treatments given to learning outcomes. Paired sample t-test results are as follows:

Table 3. Result of the paired sample t-test

\begin{tabular}{llc}
\hline & & Paired Sample Test \\
& & Sig. (2-tailed) \\
\hline Pair 1 & Post-Test Eksperimen - Pre-Test Eksperimen & 0.000 \\
Pair 2 & Post-Test Kontrol - Pre-Test Kontrol & 0.005 \\
\hline
\end{tabular}

Paired sample t-test data describe that the output of the first pair of data obtained a value of Sig. ( 2 Tailed) $<0.05$. It can be concluded that there are differences in the average of student learning outcomes for the pre-test experimental class with the post-test experimental class. Furthermore, the second pair of data output obtained a value of Sig. (2 Tailed) $<0.05$, it can be concluded that there are differences in the average student learning outcomes for the pre-test control class with the post-test control class.

The differences described by the two variables indicate that both the Youtube-Based Learning model and the conventional learning model influence student learning outcomes. To find out which variable is contributing more, it is necessary to do further tests using the independent sample t-test. 
Data homogeneity test

Table 4. Homogeneity test

\begin{tabular}{lccl}
\hline \multicolumn{3}{c}{ Test of Homogeneity of Variance } \\
\hline $\begin{array}{l}\text { Learning result of the } \\
\text { students }\end{array}$ & Based on mean & 0.868 & Information \\
\hline
\end{tabular}

Homogeneity test output data describes Sig. based on mean value $0.868>0.05$ so that it can be concluded that the variance of the post-test data of the experimental class and the post-test data of the control class is homogeneous. Thus, it has met one of the supporting test requirements from the independent sample t-test.

Independent Sample t-test

Table 5. Independent sample t-test

Independent Sample Test

\begin{tabular}{lcc} 
& Sig. (2-tailed) \\
\hline Learning result of the students & Equal variances assumed & 0.045 \\
\hline
\end{tabular}

Table 6. Descriptive analysis

\begin{tabular}{lll}
\hline \multicolumn{1}{c}{ Group Statistics } & Mean \\
\hline Learning result of the & Post-Test of Eksperimen Class & 79.15 \\
students & Post-Test of Control Class & 72.00 \\
\hline
\end{tabular}

The independent sample t-test data output shows Sig. (2-tailed) value $0.045<0.05$, so it can be concluded that there is a difference between the average learning outcomes of class students using the Youtube-Based Learning model and conventional learning models. Then, the difference of the analysis results is correlated with the average value (mean) on the descriptive analysis results in the statistical group table. It shows the mean value 79 in the experimental class and 72 in the control class. It can be concluded that the contribution given by the Youtube-Based Learning model on learning outcomes students is more significant than conventional learning models.

\section{Calculation of Effect size}

The effect size calculation aims to find out the size of the effect that the Youtube-Based Learning model gives to the student learning outcomes. This calculation is carried out by referring to the value of Cohen's d standard. The calculation of effect size in an easy way can be executed by using the online effect size calculator developed by Dr. Lee A. Becker. The results of the effect size calculations that have been carried out are as follows: 


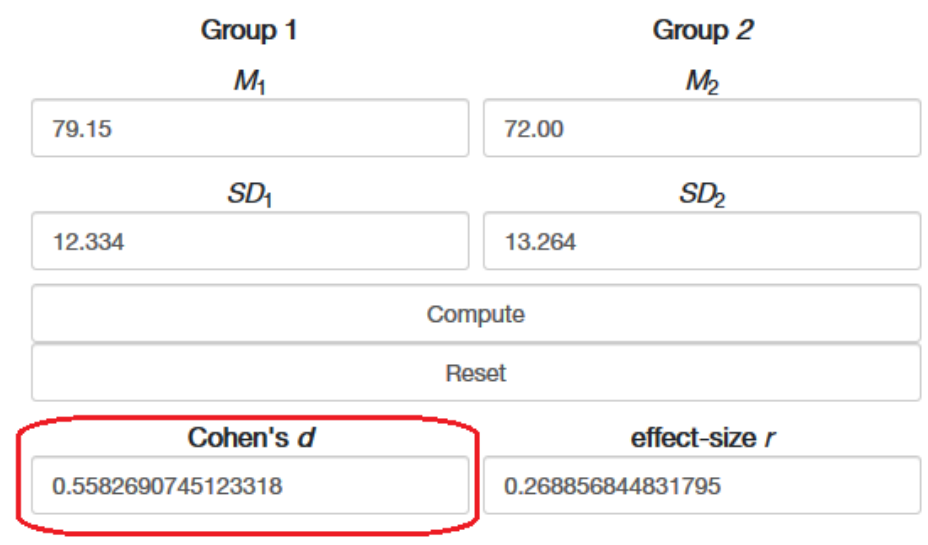

Figure 6. Result of effect size calculation

The size of the contribution given by Youtube-Based Learning models to the student learning outcomes can be analyzed from the results of calculations. The calculation showed Cohen's $d$ value 0.55 . If the value is converted to the standard percentage of Cohen's $d$, so the effect is 58\%. If the percentage is adjusted to the category in Cohen's score, so it can be concluded that the effect is included in the moderate category.

The results of the study are in line with the statement of Snelson (2011) that learning utilizing Youtube has been designed to be able to meet learning objectives in all areas of learning including cognitive, affective, or psychomotor in online learning classes. On the implementation test results, the Youtube-Based Learning model gives the contribution to the student learning outcomes. This can be interpreted that YouTube's contribution to the achievement of the cognitive aspect of learning can be proven through the results of this study.

The results of the study are also in line with Chirwa's statement which explains that, if ICT is used appropriately to support the learning and teaching process in schools and higher education, ICT can be an effective tool in the development of quality content and pedagogical learning (Chirwa, 2018)

\section{Student responses to the Youtube-Based learning model}

The result of subsequent studies is a positive response given by students to the implementation of the Youtube-Based Learning model. The reasons underlying the students' responses were the learning atmosphere became more fun and students felt freer to express their ideas through Youtube-based learning. The positive response is realized by the data of students' choice tendencies which states that students prefer and like learning using the Youtube-Based Learning model rather than conventional learning.

The positive responses which were given by students and various underlying reasons are in line with the statement of Alzaidiyeen and Almawdiah that ICTs used in learning can encourage students to express themselves, and can provide new and exciting learning experiences for students (Alzaidiyeen \& Almawdiah, 2012).

\section{Teacher responses to the Youtube-Based Learning model}

The following research result is a positive response given by the teacher. This positive response is also supported by the results of the assessment given by the teacher which states that the Youtube-Based Learning model is very feasible to implement in learning. However, in the suggestion column provided by the researcher in the research questionnaire, the teacher suggested that it would be easier for the teacher to implement the learning model if provided a complete video tutorial on the implementation of the learning model as a guide for the teacher. 
This condition is one of the evaluation materials for further improvement for researchers or can be used as suggestions for further research. On the other hand, this fact also justifies some data on the background of the research that reveals the readiness of teachers for ICT-based learning. The data was stated by the Kapustekkom of the Ministry of Education and Culture that only 40 percent of non-information and communication technology teachers were ready with technology to support learning (Suharwoto, 2018).

\section{CONCLUSION}

The conclusions of this study show that the validity of the Youtube-Based Learning model is included in the very feasible category to apply. Furthermore, the results of data analysis show that the Youtube-Based Learning model has a contribution to the student learning outcomes with a given effect of $58 \%$ and is included in the moderate category. Students give positive responses to the implementation of the Youtube-Based learning model as indicated by the tendency of students to prefer the Youtube-Based Learning model rather than the conventional learning model. Additionally, the teacher gives a positive response to the Youtube-Based Learning model and states that the validity of the Youtube-Based Learning model included in the very feasible category to apply.

\section{REFERENCES}

Alzaidiyeen, N. J., \& Almawdiah, R. S. (2012). A theoretical overview on the utilization of information and communication technology (ICT) in the educational settings. 1(2), 34-36.

APJII. (2017). Penetrasi dan prilaku pengguna internet Indonesia.

Becker, L. A. (2000). Effect Size Measures For Two Independent Groups. Effect Size Becker, 1-14.

BPS. (2018). Statistik penggunaan dan pemanfaaan teknologi informasi dan komunikasi. Jakarta: Badan Pusat Statistik.

BSNP. (2010). Paradigma pendidikan nasional abad XXI. Jakarta: Badan Standar Nasional Pendidikan.

Chirwa, M. (2018). Access and use of internet in teaching and learning at two selected teachers' colleges in Tanzania. 14(2), 4-16.

Cilliers, E. J. (2017). The challenge of teaching generation Z. 3(1), 188-198. doi: https://dx.doi.org/10.20319/pijss.2017.31.188198

Hootsuite. (2019). Time spent with media.

Sari, P. (2017). Using vlog in the youtube channel as a means to improve students' motivation and confidence to speak english in intermediate 1 level of LB-LIA Jambi. International Journal of English Language and Teaching, 1(1), 38-43.

Snelson, C. (2011). Youtube across the disciplines: a review of the literature. MERLOT Journal of Online Learning and Teaching, 7(1), 159-169.

Suharwoto, G. (2018). Kemendikbud: hanya 40 persen guru siap dengan teknologi, Republika.

Syukur, I. A. (2014). Profesionalisme guru

dalam mengimplementasikan teknologi informasi dan komunikasi di kabupaten Nganjuk. 20(2), 200-210.

Wahyudi, I. (2012). Panduan lengkap uji sertifikasi guru. Jakarta: PT Prestasi Pustakarya.

Zhu, Z., Wattenhofer, R., \& Wattenhofer, M. (2012). The youtube social network. 